Portland State University

PDXScholar

7-31-2018

\title{
Implementation of Literature Circles in Oregon Middle Schools
}

\author{
Alissa A. Conant \\ Portland State University
}

Follow this and additional works at: https://pdxscholar.library.pdx.edu/honorstheses Let us know how access to this document benefits you.

\section{Recommended Citation}

Conant, Alissa A., "Implementation of Literature Circles in Oregon Middle Schools" (2018). University Honors Theses. Paper 635.

https://doi.org/10.15760/honors.650

This Thesis is brought to you for free and open access. It has been accepted for inclusion in University Honors Theses by an authorized administrator of PDXScholar. Please contact us if we can make this document more accessible: pdxscholar@pdx.edu. 


\section{Implementation of Literature Circles In \\ Oregon Middle Schools}

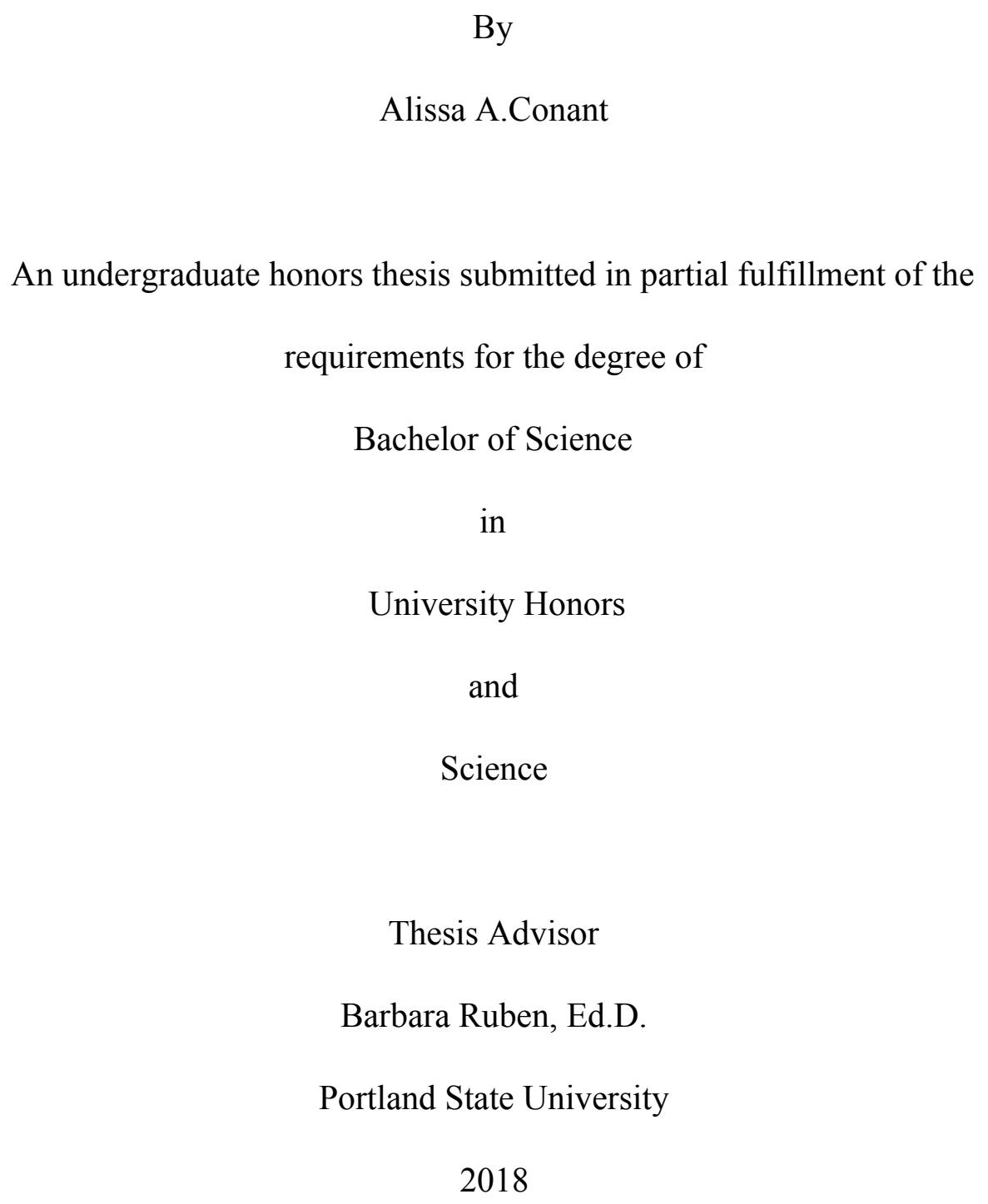




\begin{abstract}
Background: Literature circles at their most basic form are a small group discussion centered around a shared text. They have been present in the literature since the early 1990's. Today, literature circles are the subject of books, action research projects, and journal articles. Aims: The study aims to gather data on the use of literature circles through a teacher survey and teacher interviews. The goal is to ascertain how middle school teachers in Oregon are using the tool in their classroom, whether they observe positive student engagement in the practice, and to ascertain the areas in which they see literature circles impacting student outcomes.The Results: The 26 teachers who completed the survey implemented literature circles with variety. Lesser used practices included utilizing online discussions and nonfiction text. Teachers reported that social emotional learning, comprehension, literacy, and vocabulary outcomes were impacted through literature circles. Discussion: The survey gives an indication that literature circles are not a homogenous practice, but an evolving tool that can be fitted to the needs of students. Literature circles provide the opportunity for rich discussion and connection between subjects and classmates.
\end{abstract}




\section{Implementation of Literature Circles In}

\section{Oregon Middle Schools}

In my first year at Portland State University, I took a course entitled Children's Literature K-5. During the online course, students participated in a classroom experience called a literature circle. We were assigned to a small group, given a specific role accompanied by a task related to the text, and asked to spend time discussing the text online. We each focused on one aspect of the story and reported back to the group our insights, which led to a rich discussion. The practice put us in deep, direct contact with each other and the text.

Recently, I was communicating with a rural Oregon middle school teacher, and I asked the teacher whether or not they thought that the use of literature circles was widespread in Oregon. Although I know of teachers who are using the practice their classrooms, this teacher was of the opinion that very few Oregon teachers utilizing this tool. This surprised and made me wonder: how are literature circles fairing in Oregon middle school classrooms? I hypothesized that literature circles could serve Oregon students by improving not only their relationships to each other, but improve their experience with high quality children's literature as well as impact outcomes directly related to reading ability.

During a study abroad in Reggio Emilia, Italy with the Early Childhood Department at Portland State University and through the work, Making Learning Visible by Giudici et. al. (2008) I was introduced to a philosophy of education adopted by the municipal school of Reggio Emilia. The "Reggio Approach," as it is called, builds of the work of educational philosophers 
such as Dewey and Montessori and aims to support children in their own learning, in constructing their own knowledge. Reggio school have adopted the notion that children are competent constructors of their own knowledge (Guidici et al., 2008). Literature circles clearly fit within the context of this philosophy, though applied to a different age group and in the context of an American school. In Daniels' article "What's the Next Big Thing with Literature Circles," the author indicates that when implementing literature circles, teachers are not just placing students at the center of their own learning, but in the context of a peer group. The teacher changes many of the environmental aspects of a traditional classroom: students converse in small groups unaided or uninterrupted by the teacher and they often read literature of their own choosing. These two elements: the small group literary discussion and the choice of reading material are the basis of the literature circle (Daniels, 2006).

I would assert that the Oregon teachers that are using the practice of literature circles need the opportunity to share their experiences through participating in research. It is increasingly important to know how literature circles are working in classrooms today. The reason for this is twofold, it's important for teachers who might want to try implementing literature circles, but also as a reflective practice for those who are already comfortably embracing literature circles in their own classrooms. The culture and society that influence schools, teachers, and therefore children, are constantly changing and evolving. The straightforward, small group interaction with quality literature is a tool that has the flexibility to be adapted to a variety of school environments and classrooms. It is vital that we not only reflect 
on this teaching practice, but connect this tool, that has the adaptability to be culturally sensitive and effective, to teachers around the state.

My research question is, in what ways are Oregon teachers implementing small group literary discussions (commonly called literature circles) in the classroom? This research will explore the different manifestations of literature circles across Oregon and investigate the elements of the practice that are currently being utilized in Oregon classrooms. This research will also include specifically how one teacher's classroom of middle school students demonstrate motivation and interact within the framework of this tool.

\section{Literature Review}

The book Literature Circles: Voice and Choice in Book Clubs \& Reading Groups by Daniels (2002), chronicles the history of literary discussion groups, tracing modern literature circles to their origins in the education movements of the late 1980's (Daniels 2002). According to Keegan and Shrake (1991), the book The Art of Teaching Writing, inspired their action research project, one of the first to be published on literature study groups in the journal, The Reading Teacher. Some features of literature circles are present in this classroom project, including heterogeneous groups, assigned roles, discussion questions, and book choice (Keegan \& Shrake, 1991). Daniels however, (2002) identifies “Eleven Key Ingredients” that define literature circles as presented in his book. These include specific practical guidelines as well as measures related to student engagement emotion and social emotional learning:

1. Students choose their own reading materials.

2. Small temporary groups are formed, based on book choice. 
3. Different groups read different books.

4. Groups meet on a regular, predictable schedule to discuss their reading.

5. Kids use written or drawn notes to guide both their reading and discussion.

6. Discussion topics come from the students.

7. Group meetings aim to be open, neutral conversations about books, so personal connections, digressions, and open-ended questions are welcome.

8. The teacher serves as a facilitator, not a group member or instructor.

9. Evaluation is by teacher observation and student self evaluation.

10. A spirit of playfulness and fun pervades the room.

11. When books are finished, readers share with their classmates, and then new groups form around new reading choices.

Table 1.1 “Eleven Key Ingredients” (Daniels, pg 18, 2002)

Grand Conversations: Literature Groups in Action, by Peterson and Eeds (2007), also

extends the practice of small group literary discussions to build connections between school and home, allow students to build understanding through interacting with each other and the text, reading "extensively," and reading "intensively." By "extensive" reading, the authors mean for students to spend large quantities of time with books, as well as bringing the text to life through "intensive" reading, where students are able to make connections between themselves, the text, and each other. They cite the belief in the transactional process, where students engage in learning bringing their background knowledge to the text as the catalyst for learning (Peterson \& Eeds, 2007).

In more recent publications, most notably an article published in journal The Reading Teacher by Barone and Barone entitled "Really," "Not Possible," "I Can't Believe It": 
Implementation of Literature Circles

Exploring Informational Text in Literature Circles" (Barone, D \& Barone B, 2016) and the book published the following year, Literary Conversations in the Classroom: Deepening Understanding of Nonfiction and Narrative, literature circles have been relaunched as "literary conversations." In their work, there is a more prescribed outline for teachers on how to initiate the use of literature circles in the classroom. This includes grouping students heterogeneously and distributing specific roles to each student based on reading ability, as well as several examples of books choices that would work well for literature circles (Barone, D \& Baron, B, 2017).

In 2010, The U.S. Department of Education published an overview on literature circles and book clubs on the What Works Clearinghouse website (2010). The study reviewed 284 studies on literary discussion groups and included book clubs and literature circles within the framework of inquiry. The majority of these studies were conducted between 1998 and 2009, the most prolific time period was between 1998-2003. The number of studies published shows that literature circles gained momentum in the late 1990's (WWC, 2010) and this increase coincided with the 1994 publication of Daniels' Literature Circles: Voice and Choice in the Student-centered Classroom. According to Daniels (1994), in the 1980's, teachers were experimenting with book clubs in their own classrooms (Daniels, 1994).

Within the framework criteria of the Adolescent Literacy Evidence Review Protocol (ALERP), the WWC conducted their study to ascertain the validity of literature circles as an evidence based practice. However, the WWC overview was not able to validate a single study that met the criteria outlined in the ALERP, (WWC 2010) bringing into sharp contrast the 
priorities and methods of the wider education community and the goals and methodology promoted by the United States Department of Education through the vehicle of the WWC.

Since the study done in 2010, there have been additional research papers and books published on the efficacy of literature circles and their use. Through a review of a collection of 76 studies published from 2010-2018 searchable through the Education Research Complete database, using the key word "literature circles," the dissertation, Whitworth's "Using Literature Circles to Enhance Student Knowledge of Non-Fiction Text," (Whitworth, 2017) emerged as one paper that met the guidelines of the ALERP from the WWC and showed that literature circles had a significant impact on student's ability to read and interpret non-fiction text compared to a control group using teacher led, whole group learning. This research showed improvement preand post-test of both groups, but a greater improvement in the reading ability of the literature circle group (Whitworth, 2017). Whitworth (2017) illuminates the power of literature circles to improve reading within the context of scientific inquiry and is an important step toward building a body of evidence that bridges the gap between the robust evidence on the efficacy of literature circles and the demands of the U.S. Department of Education when validating educational research.

Because there is so much research on literature circles available, but very few studies designed using methods accepted by the United States Department of Education, it is possible that teachers will find less support for the practice moving forward. This lack of support can be inferred from the sharp decline in studies published on literature circles in the United States in the last eight years. 
What is really going on in classrooms that currently use literature circles and how do teachers perceive their impact on student outcomes? Because the use of literature circles is by nature non-prescriptive and open ended, (Daniels, 2002) there is a potential difficulty in sifting through the evidence to distill the elements that consistently work in the classroom.

Furthermore, if the essential building blocks of literature circles are not the particulars, and if the very act of participating in small group discussions with a text independent of a teacher one catalyst for impacting the growth of readers, then a less prescriptive approach to literature circles may be the most effective way forward.

Looking outside the context of American education, we can draw inspiration and possible answers to these questions in the distant work of the early childhood educators in Reggio Emilia, Italy. The Reggio Emilia approach sees children as "active constructors of their own learning and participators and producers of original points of view" (Guidici et al., 2008).

"The focus of learning in learning groups extends beyond the learning of individuals to $\mathrm{c}$ create a collective body of knowledge. Learning groups, in our view are much like scientific communities or scholarly disciplines in that they focus on building collective as well as individual knowledge...Reggio schools are seen as a place to document human learning, places where children's' voice can be heard, respected, and shared with the wider community." (Guidici et al., 293)

\section{Methods}

First, a search of the Education Research Complete database (EBSCO Publishing, 2006) was conducted using the key words, "literature circles." The search parameters were set 
between October 2010 and March 2018. The search yielded 76 results. A sample of 15 were analyzed for the eligibility criteria outlined by the WWC study of literature circles/book clubs. This included population, types of interventions, study design, outcomes, and evidence standards from the ALERP done on literature circles and book clubs published on the WWC website (2010).

With the guidance and encouragement from my advisor, B. Ruben, I created a thirty question survey that addressed basic demographics and elements of literature circles the goal of ascertaining the status of literature circle use in Oregon middle school English language arts (ELA) classrooms grades six through eight. The survey included a partial, modified measure of student engagement behavior and engagement emotion that had been created by Wellborn (1991) and modified and validated by Chi and Skinner (Wellborn, 1991; and Chi \& Skinner, 2010). In addition, questions measured the perception of teachers in middle school ELA classrooms about the effectiveness of literature circles in their classroom and the perceived impact on student learning. Interview questions were also created so a more in depth perspective on teachers' experiences with literature circles could be obtained and coded.

Over 200 Oregon middle school language arts teachers received an invitation to participate in the survey through direct email or indirectly through the principal of the school. Teachers were also reached out to through a local English teacher organization. Finally, the same large group of teachers were invited to participate in the interview portion of the study by direct email, through their school principal, or through the ELA teacher association. The interview would take place on one day and would consist of seven questions. 


\section{Results}

\section{Participants}

27 teachers consented to the study and 26 completed all 30 questions. One survey respondent agreed to participate in an interview.

\section{Demographics: Schools and Teacher Experience}

Teachers were asked to identify some basic demographics of their school, and the respondents included $17.86 \%$ from urban areas, $42.86 \%$ from suburban areas, and $39.29 \%$ from rural Oregon. This distribution does not reflect the overall demographics of the state. According to the data from the Annual Oregon Population Report (2014) slightly over $20 \%$ of the population is from non-metropolitan areas, with the remaining nearly $80 \%$ of residents occupying metropolitan areas including towns such as Corvallis, Albany, Bend, and Grants Pass, which all had a population of less than 200,000 each.

Additional demographics included rates of free or reduced lunch, with 9 of the 27 respondents identified their school as having less than $40 \%$ of students who received free or reduced lunch. According to the Oregon Department of Education (2018), 50.2\% of all middle school students are eligible for free and reduced lunch. Finally, a total of 2 teachers indicated that more than $60 \%$ of the students at their school identified as being a part of a minority group. 15 schools had less than $20 \%$ of students who identified as minorities, while the rest of the schools of the teachers surveyed fell in between that range. According to the Oregon Department of Education (2018), 37.08\% of students enrolled at Oregon schools are students of color. 
Teachers themselves varied in their experience in the classroom and with implementing literature circles. Both the most experienced and inexperienced teachers equally made up over half of the respondents, $57.14 \%$ of teachers surveyed had taught either less than five years or over 17 years. 17 teachers had been teaching more than 10 years. $73.08 \%$, the majority of all teachers, regardless of experience, had used literature circles 1-3 times in their current classroom. There were $15.38 \%$ of teachers surveyed that indicated they had used literature circles more than 12 times in their current English Language Arts classroom. During the 2017-2018 academic year, 21 out of the 28 teachers surveyed had either used literature circles, however $25 \%$ had not and were not planning to implement the tool by the end of the year.

\section{Structure of Literature Circles}

The structure of literature circles can be quite open ended, but the common thread, whether students have special needs (Anderson, 2008) or have English as their second language (Elhess \& Egbert 2015), are using the tool with a textbook (Wilfong 2009), or across multiply grades (Helgeson, 2017), is that essentially a small group of students read and discuss a book together. It was not surprising then, that even in light of the more recent prescribed model of literature circles (Barone \& Barone, 2017) the way that teachers in this survey implemented literature circles varied. Some specific aspects of literature circles that were not widely used by these teachers included online student led discussions and the use of non-fiction text. In research with second grade bilingual students using literary discussion groups, Osorio (2018) notes that,

Every student offers his or her unique story and brings (their) own knowledge to learning...my research demonstrated that students' ability to have meaningful and 
Implementation of Literature Circles

detailed conversations, comprehend text by connecting to personal experiences, engage as leaders, and communicated with peers clearly- all characteristics contributing to students as readers. Further, when students authentically expressed themselves and their intense personal stories, demonstrated leadership when given the opportunity, and connected a character's narratives in relevant ways, my classroom came alive with meaning. (Parnell \& Iirio 2018)

The teacher interviewed for this study provided students with reading response journals, an assessment tool that the teacher had also used for books that were read as a whole class. This writing and comprehension tool, as described in Gordon's article, "Using a Reading Response Journal," sometimes contains open ended questions about the text, but encourages students to choose lines that are meaningful to them and then complete a free write about the text (Gordon 2000).

\section{Heterogeneous Grouping}

Heterogeneous grouping has been suggested as a way to implement literature circles with the goal of meeting the needs of students with a variety of reading abilities. (Barone \& Barone, 2016) In this survey, heterogeneous grouping did not occur consistently across the population. There was an almost even distribution of those who did or did not group students heterogeneously. During the teacher interview, it became clear that grouping students together heterogeneously was a question of access for this teacher. When discussing access for students who aren't able to read independently at even the lowest level, resources became a problem as well, 
“...if I'd had audio books for (students reading below grade level), that might have worked...I think the lowest (of the three books assigned to groups) was a black level, which is what grade, second? Third? And anybody that is reading below that couldn't access the lowest book..."

Although some may suggest using adaptations of the same book for students who cannot access the text, audio books, whether on stand alone players, tape, or cd, are the preferred support for students participating in literature circles in an inclusionary or resource classroom (Anderson \& Corbett, 2008). There is the potential that resources alone may create more opportunity for heterogeneous grouping.

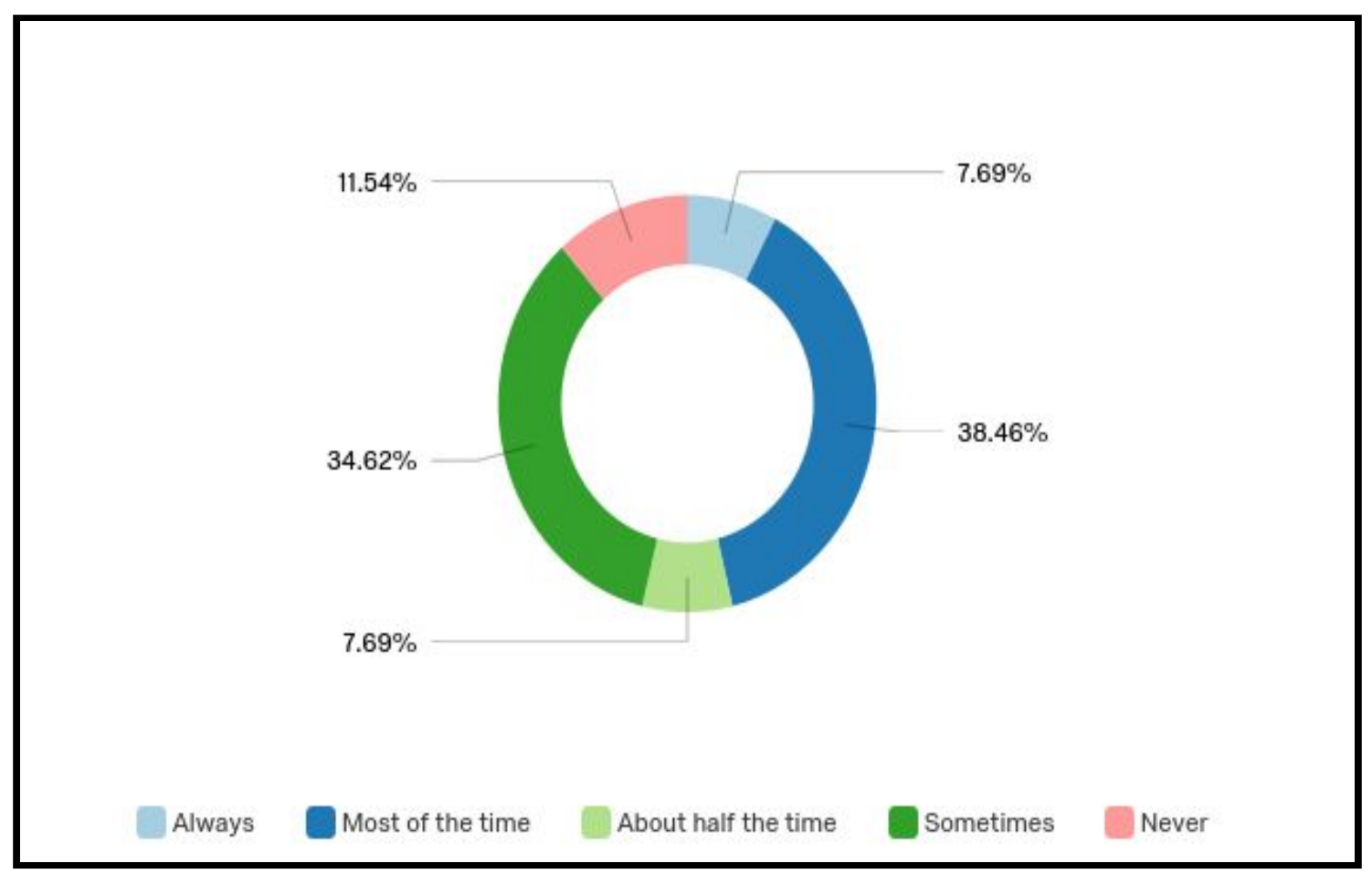

Table 1.2 Heterogeneous Grouping of Students

Where Students Read Text 
Students were expected to read the text either in class or both at home and in class over $96 \%$ of the time. Over $50 \%$ of teachers expected students to read the text both at school and at home, indicating that the resources were available in $50 \%$ of classrooms surveyed for students to do so. The teacher stated:

"I was teaching at the same time as our other 7 th grade language arts teacher and between the two of us, we had 350 students so we had enough books to be in our classroom, but we did not have enough books for kids to take home, and so what I ended up doing was finding a pdf of the books online."

However, not all the teacher's students have computer access at home. Even though the teacher counts this experience as a success and something worth repeating, "there were still some kids who didn't have enough access to the reading materials."

Results showed that half of teachers surveyed were also able to provide groups with a book of their own choosing most of the time. Teachers used a variety of text groupings in their literature circles, sometimes providing students with texts by genre, author, topic, protagonist gender. Over $20 \%$ of teachers had used one book for the entire class, but more frequently, teachers provided more than one book for the students in their classroom. 


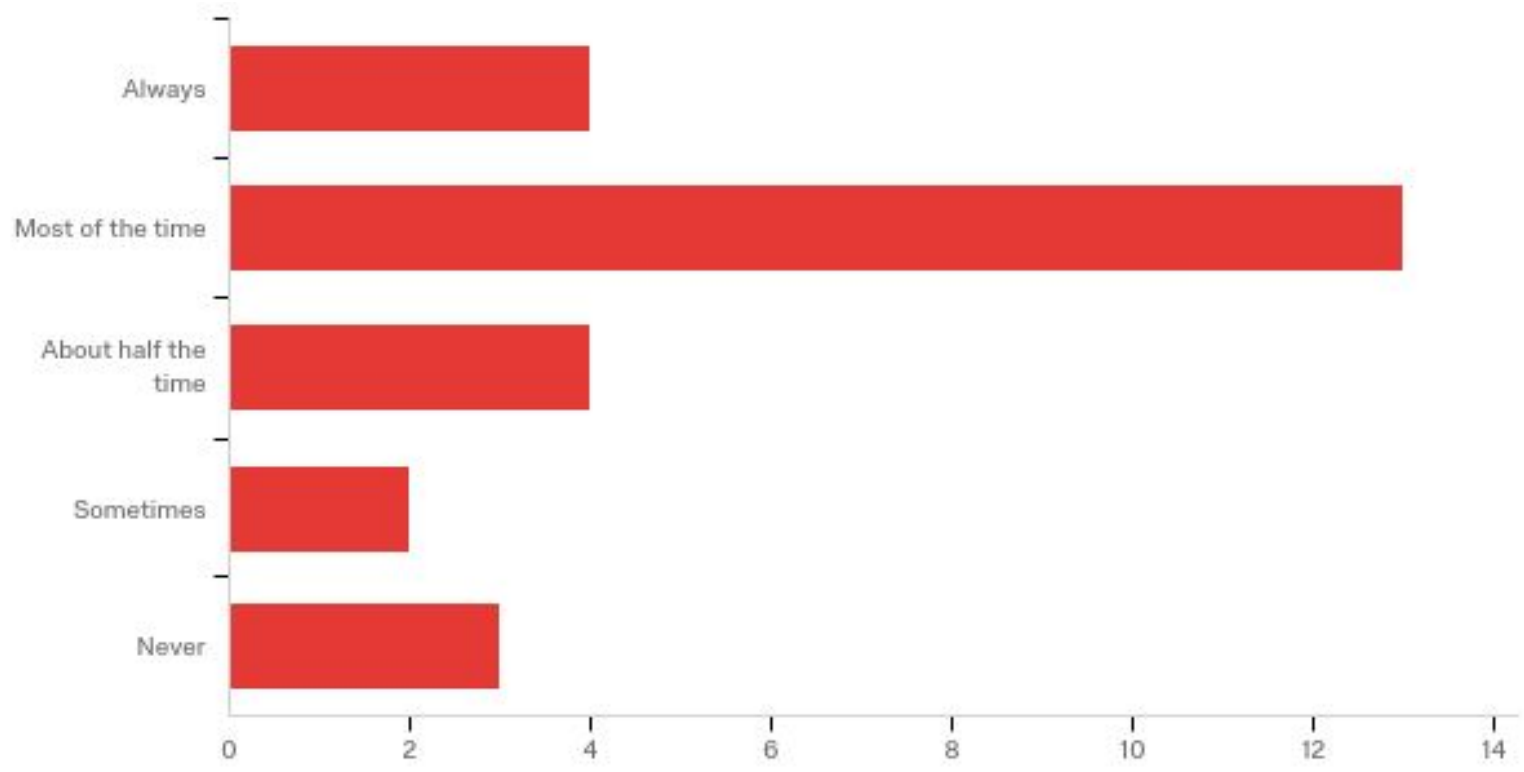

Table 1.3 How often teachers allow students to read books of their own choosing.

Though the interviewee, who had success with the recent classroom, assigned students to books based on reading level.

"I was smart enough to realize that they did not all read at grade level. So we had the three different levels of books, and then I assigned them the book they were going to read, which unfortunately takes that choice away, but at least they were all reading books that were about the same subject...they did a really good job this time, everybody was reading. So having a book at their level, I think really helped; and the books were all pretty good, so I think that helped too."

\section{Online Discussions and Non-Fiction Text}

The findings of this survey indicate that online discussion groups and non-fiction text did not often find its way into ELA classroom literature circles. Online discussions and nonfiction 
text were utilized every time by only one respondent each, and $69 \%$ of teachers reported never using online discussions. Nonfiction text was never used by over $26 \%$ of teachers.

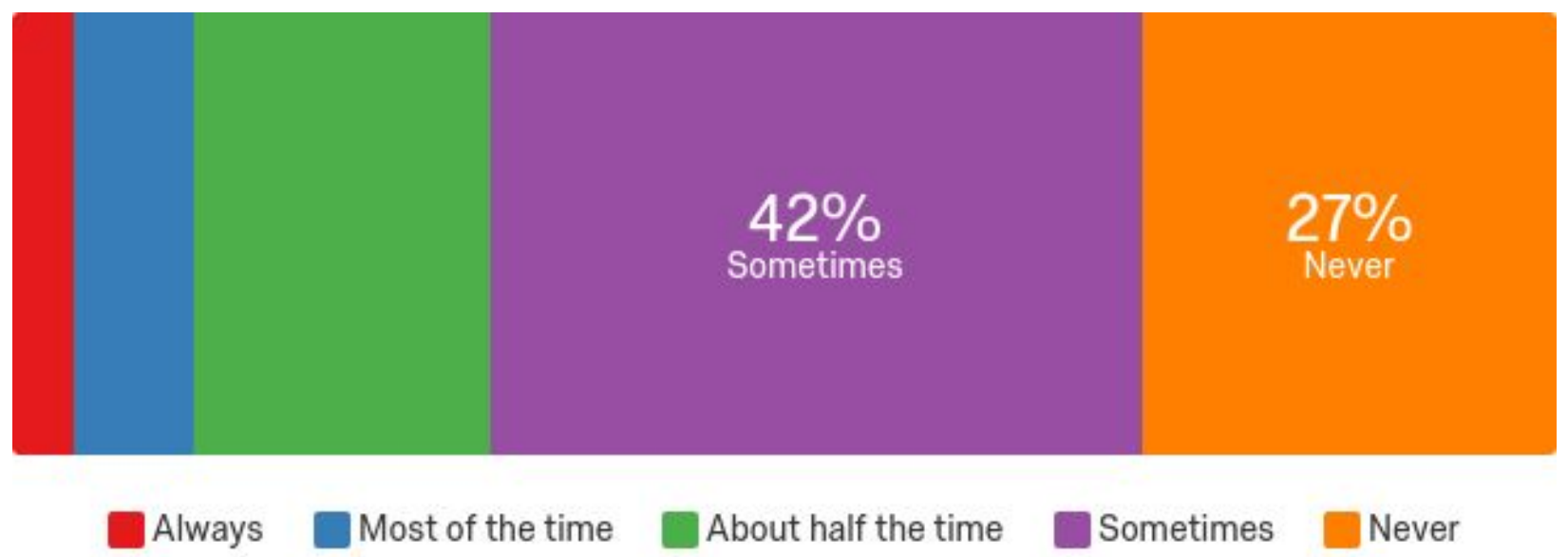

Table 1.4 Survey Question: "How often do you use non-fiction text in literature circles?"

Nonfiction text has been encouraged in literature circles (Barone, D \& Barone, B, 2016; Daniels 2002) and online discussions have been shown to work well within the practice of literature circles. (Whittingham, 2013; Bowers-Campbell, 2011; Larson, 2009) There may be a gap in the research between the use of non-fiction text in literature circles and the impact that non-fiction plays in discussions. In the interviewee's classroom, the teacher utilized the three weeks of pre-teaching to introduce background knowledge about the subject of World War II, and noted that students eagerly made connections between the literature circle's historical fiction text and what they were learning in social studies,

"They would make connections to other times in history that I hadn't made or thought that you could see. They'd attach it to something that they were talking about in social studies that maybe I didn't know they were studying in social studies. So, for them, they own more of that knowledge when they can connect it to other knowledge and that helps 
Implementation of Literature Circles

solidify everything...There was vocabulary that they knew because they had learned it in another class...it just made the whole experience much richer..."

The teacher also reported of the students:

“...they had a depth of knowledge I didn't realize. They were more aware of some things than I thought about. They really looked at the human aspects of what was going on and questioned, well, why did people do that? And (the class was) able to have really rich conversations..."

This is reflected in a practice put forth by Brown in the article, "Transaction Circles with Digital Texts as a Foundation for Democratic Practices," in which the author suggests a more reductionist approach to literature circles based on Rosenblatt's transactional theory (Brown 2015). Although this teacher did not engage the students with digital text, historical fiction and a simplified model was used, which may have allowed for greater freedom of thought in the classroom, especially when making connections between their own individual background knowledge, their collective understanding through the social studies curriculum and the text they studied in ELA.

\section{Student Engagement}

Teachers perception of student engagement during the use of literature circles was overall positive. When asked if students do more than is required when it comes to literature circles, 10 of the 26 teachers surveyed either somewhat or strongly agreed with the statement: over $38 \%$ of ELA teachers experiencing increased student output while using literature circles. $57.69 \%$ of teachers also reported that overall, they either strongly or somewhat agreed that students were 
reading the text carefully and coming to class prepared. None of the teachers surveyed strongly disagreed with the statement about careful reading and preparation.

Teachers also reported that they observed that students participate in discussions, work as

hard as they can, listen carefully to explanations of new material, appear involved, feel good, and are enthusiastic when beginning literature circles. Even when starting literature circles, $88.46 \%$ of teachers either somewhat or strongly agreed that students participate in discussions. In the interview, the teacher stated:

"When you have a whole class discussion, you have a few kids talking, usually the same kids. And in the smaller group conversations, the kids that normally don't speak were more comfortable. After a while they would actually start saying things and you could listen to what they were thinking, what their thoughts were, and they had a lot to add. So

I feel (the students) had a lot more buy in and knew that they needed to say something. Nobody wanted to sit there and not say anything."

\section{Challenges of Implementation}

The process of implementing literature circles does not go smoothly for all teachers. $23.08 \%$ of teachers surveyed indicated that they somewhat disagreed with the statement that literature circles worked well for them in their classroom. Although the majority of teachers, 19 out of the 26 surveyed, either somewhat or strongly agreed with the statement that literature circles did work well for them in their classroom, the six language arts teachers that were not having success in the classroom is a concern. The interviewee cited resources as one challenge 
faced in the classroom: whether simply finding books that grouped well together and met the reading level needs of students, or having enough books for students to access the text at home. Teaching experience and forgoing the use of roles was key attributed to eventual success:

"The first time (used literature circles) I was teaching middle school...at that point I had 7th and 8th graders in mixed classes...that was the first time I tried to do it and tried to do the role thing and it failed miserably. It took me a really long time to try it again," the teacher stated. "At that point in time, getting them to read at all was challenging...I was a fairly new teacher and I wasn't good at aligning the materials with their skill levels, so I should have, in reflecting back now, I realize some of them were reading books...that interested them, rather than (books at) their reading level.”

This year, the interviewee tried grouping different levels of books together by genre, (she chose a unit on World War II), providing nearly three weeks of background information on the subject matter; and assigning students books at three different reading levels. The teacher also eliminated the use of assigned roles.

The teacher stated:

"So I had done (literature circles) a long time ago, and then I had kind of done minor attempts at it in the past, but this was the first successful attempt... it worked really well. (I kept thinking) 'I love this, I want to keep doing this thing that I did." The success with eliminating roles may go a bit further than some, but this interview echoes what Daniels' has been encouraging for quite some time, "I wrote articles, developed a website, 
gave speeches, and ultimately wrote a new edition of the book with much stronger cautions about the mechanical discussions that can stem from over-dependence on these roles" (Daniels, 2006).

The teacher plans to expand the practice next year include offering students more choice. The teacher reported:

“...what I'd like to do now, is try to do it where they can choose a novel of their own interest. Maybe the novels don't all have to be related, but they can choose something at their reading level that they are interested in reading and have five or six people who all want to read the same book and have them do it that way. That's difficult, because then you have to prepare the reading journal, response journal, things that they need to do in the class for each book that they need to read...you have to give them an option of 'here are seven books' or 'here are a couple books at each level.' That gets more complicated and more it's really work intensive up front for the teacher, but then you just sit there just watching them read and learn... It was a thing of beauty watching them take it and discuss it and get their own meaning."

\section{Student Outcomes}

The WWC study on literature circles and book clubs was focused on student outcomes related to literacy (WWC 2010). In order to gain insight into the types of outcomes the surveyed teachers in our group were observing in their classrooms, they were asked to identify the areas that literature circles had impacted their students. The results highlighted three main areas of impact: literacy, reading ability, and social emotional learning. Teachers reported that they saw literature circles as having a positive impact on overall student literacy and reading ability. 
$84.61 \%$ of respondents strongly or somewhat agreed that literature circles had a positive impact on student overall literacy. $76.93 \%$ of teachers surveyed strongly or somewhat agreed that the reading ability of their students benefit from the practice. Furthermore, the impact of literature circles on social emotional learning was observed by over $90 \%$ of teachers, followed by the teachers' perception of the impact of literature circles on literacy $(88.46 \%)$, comprehension $(84.62 \%)$ or vocabulary $(80.77 \%)$ outcomes. Motivation, language, and reading ability followed as the next three highest reported outcomes.

\section{Discussion}

\section{Limitations}

There were many limitations to this study. First of all, timing was an issue. The academic year was wrapping up, and conceivably that was why it was difficult to get teachers, who are understandably busy, to participate in the interview portion of the research and give up time during the summer to do so. However, in the future, replicating the study could potentially be much easier.

Another problem came in direct recruiting of urban schools. In the case of Portland Public Schools, the largest school district in the state, teachers could only be reached through the site coordinator or through the local English teacher association. There was direct accessibility to most rural and suburban schools teachers, which made up the bulk of the contact list and made up the majority of the survey respondents.

The study was also limited due to the anonymity of the research. Although it is important to protect privacy, gathering more specific demographic information and the names and schools 
of participants would have been helpful for following up in recruiting interviewees. Since the study was limited to adult participants, having the same participants complete the same survey after a specified time period, could have established a margin of error for future use of this tool. Since the teachers were self reporting, going back to survey them again could have given insight into the validity of the original results.

Unfortunately, the interview portion of the study was limited to anecdotal evidence because there was only one participant. However, further studies done with the same interview questions could provide a more robust body of evidence that could be coded. This one interview illuminated another flaw: the gap in connecting non-fiction text used in pre-teaching as part of the practice of literature circles, particularly when using historical fiction.

Finally, the literature review of studies done since 2010 was not comprehensive. There are many other databases that the WWC (2010) work searched for their study as well as additional papers that have been published since the research on that portion of the paper was completed.

\section{Conclusion and Further Study}

I believe that connecting the research and ideas about literature circles to the practical classroom experience of more teachers is important. Gathering more survey data from teachers around the country and conducting more interviews would be a way of validating this initial research and to begin to get a better overview of what is working overall in classrooms around the country. This kind of research could potentially help guide more in depth action research on literature circles and their effectiveness as an educational tool, particularly when connecting 
historical fiction to social studies or other disciplines. Another avenue of further research would be to validate variations of literature circles: the success that one teacher had without the use of assigned roles is something that could be further investigated. Furthermore, the overwhelming $90 \%$ of teachers that literature circles impacted social emotional learning outcomes should be noted and further investigated.

My own definition of literature circles has been distilled down to the basic elements of a small group discussion focused on a particular text. The particulars, for instance how many students are in a group or whether the text is nonfiction or fiction, varied within the context of this study and within much of the literature. It begs the question: why does the act of creating this particular learning environment work? It is created by dedicated teachers who plan and prepare, gather resources, labor over group dynamics, and give the text as a provocation, to borrow the phrase so often used in Reggio Emilia, so that students can have the opportunity to create their own experiences together. I would argue, literature circles keep the work of the student at the center of the classroom. It is essentially a democratic practice, where students find themselves and their voices at the center of learning.

The survey gives an indication that literature circles are not a homogenous practice, but an evolving tool that can be fitted to the needs of students. Every generation, every cohort, every classroom is unique. The culture and society that influence schools, teachers, and therefore children, are constantly changing and evolving. Straightforward, small group interaction with quality literature is a tool that has the flexibility to be adapted to a variety of school environments and classrooms. 
Literature circles can provide the opportunity for rich discussion and connection between course subjects and classmates. I would hope that the Oregon teachers that are using literature circles find themselves and their practice represented in this research. It believe it is increasingly important to know how literature circles are working in classrooms today: it's important for teachers who might want to try implementing literature circles, but also as a reflective practice for those who are already comfortably embracing literature circles in their own classrooms.

From my time in Reggio Emilia and the work of Rinaldi, In dialogue with Reggio Emilia: Listening, researching and learning, I came to the understanding that it is our historical responsibility not only first to respect the competency of the child, but to create cultural, social, political, and educational contexts which are able to receive children and dialogue with their potential for constructing democracy. Literature circles are physical contexts, but they are also mental contexts which require the deconstruction and overcoming of our preconceptions about childhood. Engaging with literature in small group discussion has the potential to give children the ability to create a new culture of childhood and a new identity for ourselves as educators. (Rinaldi, 2006) In conclusion, the interviewee commented on this impact of literature circles on student learning:

"It was a thing of beauty watching them take (the book) and discuss it and get their own meaning out of it... They had a depth of knowledge I didn't realize; they were more aware of some things than I'd thought...They really looked at the human aspects of what was going on and questioned, well, why did people do that? And (students) were able to have really rich conversations..." 


\section{Acknowledgements}

I would like to thank all who contributed to the construction of this paper. First of all, thank you to my advisor, Professor Emeritus Barb Ruben, for her faithful guidance. I'd also like to acknowledge Instructor Dolores Johnson, who introduced me to the beauties of children's literature in a way that I would never had experienced without her guidance. To Penny Plavala, who graciously reached out to ELA teachers on my behalf, thank you for your generosity. Thank you Taylor Siron and Kristin Lebsack, teachers who supported this work with ideas and illuminating conversation. Also special thanks to Professors Will Parnell, John Nimmo and Jeanne Marie Iorio, as well as all the faculty at the Helen Gordon Child Development Center and students in the Early Childhood Education programs at Portland State University and the University of Victoria, Melbourne who welcomed me on an amazing journey to Reggio Emilia, Italy. And last and not least, thanks to my husband and children who encouraged me and supported me as I finished my undergraduate studies. 


\section{References}

Anderson, Peggy L., and LeAnn Corbett. "Literature Circles for Students With Learning Disabilities." Intervention in School and Clinic, July 16, 2008. https://doi.org/10.1177/1053451208318681.

Barone, Diane, and Barone, Rebecca. Literary Conversations in the Classroom: Deepening Understanding of Nonfiction and Narrative. New York, NY: Teachers College Press, 2017.

Barone, Diane, and Rebecca Barone. “'Really,' 'Not Possible,' 'I Can't Believe It': Exploring Informational Text in Literature Circles.” Reading Teacher 70, no. 1 (July 1, 2016): 69-81.

Bowers-Campbell, Joy. “Take It Out of Class: Exploring Virtual Literature Circles.” Journal of Adolescent \& Adult Literacy 54, no. 8 (May 1, 2011): 557-67. https://doi.org/10.1598/JAAL.54.8.1.

Brown, Sally. (2015). Transaction Circles with Digital Texts as a Foundation for Democratic Practices. Democracy \& Education, 23(2), Democracy \& Education, 2015, Vol.23(2). Calkins, Lucy McCormick. The Art of Teaching Writing., 1986.

Chi, U., Skinner, E. A., \& Kindermann, T. A. (2010). Engagement and Disaffection in the College Classroom: Construction and Validation of a Measurement Tool to Assess Students' Motivation to Learn. Technical Report, Portland State University. Daniels, H. (1994). Literature circles : Voice and choice in the student-centered classroom. York, Me.: Stenhouse. 
Daniels, Harvey. Literature Circles: Voice and Choice in Book Clubs and Reading Groups. Stenhouse Publishers, 2002.

Daniels, H. (2006). What's the Next Big Thing with Literature Circles?. Voices From The Middle, 13(4), 10-15.

EBSCO Publishing. (2006). Education research complete. Ispwich, MA: EBSCO Pub.

Eeds, Maryann, and Deborah Wells. "Grand Conversations: An Exploration of Meaning Construction in Literature Study Groups." Research in the Teaching of English 23, no. 1 (1989): 4-29.

Elhess, Mohamed, \& Egbert, Joy. (2015). Literature Circles as Support for Language Development. English Teaching Forum, 53(3), 13-21.

Giudici, C., Rinaldi, Carlina, Krechevsky, Mara, Barchi, Paola, Gardner, Howard, Filippini, Tiziana, ... Municipal Infant-toddler Centers Preschools of Reggio Emilia. (2008). Making learning visible : Children as individual and group learners. Cambridge, MA : Reggio Emilia, Italy: Project Zero, Harvard Graduate School of Education ; Reggio Children, International Center for the Defense and Promotion of the Rights and Potential of all Children.

Gordon, Heather G. (2000). Using a Reading Response Journal. Teaching English in the Two-Year College, 28(1), 41-Year College, 2000, Vol.28(1), p.41-43. Helgeson, John. "Differentiating Through Literature Circles." Kappa Delta Pi Record 53, no. 1 (January 2, 2017): 41-44. https://doi.org/10.1080/00228958.2016.1264821. 
Heller, Mary F. “Telling Stories and Talking Facts: First Graders' Engagements in a Nonfiction Book Club.” The Reading Teacher 60, no. 4 (December 1, 2006): 358-69. https://doi.org/10.1598/RT.60.4.5.

Keegan, Suzi \& Shrake, Karen. "Literature Study- Groups: an Alternative to Ability Grouping." Reading Teacher 44, no. 8 (199104): 542-47.

Larson, Lotta C. "Reader Response Meets New Literacies: Empowering Readers in Online Learning Communities.” The Reading Teacher 62, no. 8 (May 1, 2009): 638-48. https://doi.org/10.1598/RT.62.8.2.

Report Card Download - Oregon Department of Education. (n.d.). Retrieved January 31, 2018, from http://www.ode.state.or.us/data/reportcard/reports.aspx

Parnell, W., \& Iorio, Jeanne Marie. (2016). Disrupting early childhood education research : Imagining new possibilities (Changing images of early childhood). New York: Routledge.

Peterson, R., \& Eeds, Maryann. (2007). Grand conversations: Literature groups in action (Updated ed., Bright idea). New York: Scholastic.

Rinaldi, C. (2006). In dialogue with Reggio Emilia : Listening, researching and learning (Contesting early childhood). London; New York: Routledge.

Skinner, E. A., Kindermann, T. A., \& Furrer, C. (in press).

Wellborn, J. G. (1991). Engaged and disaffected action: The conceptualization and measurement of motivation in the academic domain. Unpublished doctoral dissertation, University of Rochester, New York. 
Whittingham, Jeff. "Literature Circles: A Perfect Match for Online Instruction.” TechTrends 57, no. 4 (July 1, 2013): 53-58. https://doi.org/10.1007/s11528-013-0678-5.

Whitworth, Amanda. (2017). ProQuest LLC, ProQuest LLC, 2017, Vol.ersity(,).

Wilfong, Lori G. "Textmasters: Bringing Literature Circles to Textbook Reading across the Curriculum." Journal of Adolescent \& Adult Literacy 53, no. 2 (2009): 164-71.

"WWC | Adolescent Literacy Evidence Review Protocol.” Accessed February 10, 2018. https://ies.ed.gov/ncee/wwc/Document/29.

“WWC | Book Clubs.” Accessed February 10, 2018. https://ies.ed.gov/ncee/wwc/EvidenceSnapshot/49. 


\section{Appendix A}

\section{Survey Questions: Implementation of Literature Circles in the Middle Grades}

Section 1: Demographics

Which category best describes your current school?

Urban

Suburban

Rural

How many years have you taught?

0-5

6-10

11-16

$17+$

What is the percentage of students at your school who qualify for free or reduced lunch?

$0-20 \%$

$21-40 \%$

41-60\%

$61-80 \%$ 
Implementation of Literature Circles

$81 \%$ or more

What is the percentage of students at your school are a minorities?

$0-20 \%$

$21-40 \%$

$41-60 \%$

$61-80 \%$

$81 \%$ or more

Section 2: Literature Circle Implementation

Approximately how many times have you used literature circles in your current English Language Arts (ELA) classroom?

1-3

4-7

8-12

13 or more

Have you implemented at least one literature circle in your class in 2017-2018?

Yes

No 
Implementation of Literature Circles

No, but I plan to do so

How often do you group your students heterogeneously?

Always

Very Often

Sometimes

Rarely

Never

When are your students expected to read the text?

At home

In class

Both

How often do you allow groups to read a book of their own choosing?
Always
Very Often
Sometimes
Rarely

Never 
In what ways have you grouped the text used in literature circles?

One book for the entire class

\section{By Genre}

By Author

By Topic

By Protagonist Gender

Other

How many students are you most likely to assign to each literature circle?

3 or fewer students per group

4 students per group

5 students per group

6 or more students per group

How often do you to offer extension projects?
Always
Very Often
Sometimes
Rarely

Never 
How frequently do you utilize online discussions for literature circles?
Always
Very Often

Sometimes

Rarely

Never

How often do you use non-fiction text in literature circles?
Always
Very Often

Sometimes

Rarely

Never

Section 3: Student Engagement and Behavior and Engagement Emotion

When we first start new literature circles, overall my students participate in discussions.

Strongly Disagree

Disagree

Neutral

Agree 
Implementation of Literature Circles

Strongly Agree

When participating in literature circles, overall my students work as hard as they can.

Strongly Disagree

Disagree

Neutral

Agree

Strongly Agree

When I explain new material related to literature circles, overall my students listen carefully.

Strongly Disagree

Disagree

Neutral

Agree

Strongly Agree

Overall, my students do more than is required when it comes to literature circles.

Strongly Disagree

Disagree

Neutral 
Implementation of Literature Circles

Agree

Strongly Agree

When we start literature circles in class, overall my students are enthusiastic.

Strongly Disagree

Disagree

Neutral

Agree

Strongly Agree

During literature circles, overall my students appear involved.

Strongly Disagree

Disagree

Neutral

Agree

Strongly Agree

When participating in literature circles, overall my students seem to feel good.

Strongly Disagree

Disagree

Neutral 
Implementation of Literature Circles

Agree

Strongly Agree

During literature circles, overall my students read the text carefully and come to class prepared.

Strongly Disagree

Disagree

Neutral

Agree

Strongly Agree

Section 4: Student Outcomes

Literature Circles have a positive impact on my students' motivation in class.

Strongly Disagree

Disagree

Neutral

Agree

Strongly Agree 
Implementation of Literature Circles

Literature Circles have a positive impact on my students' overall literacy.

Strongly Disagree

Disagree

Neutral

Agree

Strongly Agree

Literature Circles improve my students' reading ability.

Strongly Disagree

Disagree

Neutral

Agree

Strongly Agree

Literature Circles work well for me in my class.

Strongly Disagree

Disagree

Neutral

Agree

Strongly Agree 
Implementation of Literature Circles

Literature Circles impact the following student outcomes (check all that apply)

Literacy

Comprehension

Fluency

Reading Ability

Aural Learning

Language

Phonemic Awareness

Phonetics

Vocabulary

Vocalization

Word Recognition

Alphabetics

Motivation

Social Emotional Learning

Other 


\section{Appendix B}

\section{Teacher Interview Questions}

1. How would you define literature circles?

2. When were you first introduced to literature circles as a teaching practice?

3. Do you remember the first time you ran a literature circle in your class? Do you remember any specific challenges? Any specific successes?

4. How has your practice changed from that first time until now?

5. What do you think is biggest benefit to your students who participate in a small group discussion like this?

6. What are the biggest challenges for implementing this practice moving forward? In what ways do you see your practice evolving in the future?

7. What do you think the students come away with at the end of this practice? 